\title{
Pressure Oscillations and Structural Vibrations in Space Shuttle RSRM and ETM-3 Motors
}

\author{
D. R. Mason , R. A. Morstadt ${ }^{\dagger}$, S. M. Cannon ${ }^{\ddagger}$, E. G. Gross ${ }^{\S}$ and D. B. Nielsen \\ ATK Thiokol, an Alliant Techsystems affiliate, Brigham City, Utah 84302
}

The complex interactions between internal motor pressure oscillations resulting from vortex shedding, the motor's internal acoustic modes, and the motor's structural vibration modes were assessed for the Space Shuttle four-segment booster Reusable Solid Rocket Motor and for the five-segment engineering test motor ETM-3. Two approaches were applied: 1) a predictive procedure based on numerically solving modal representations of a solid rocket motor's acoustic equations of motion and 2) a computational fluid dynamics twodimensional axi-symmetric large eddy simulation at discrete motor burn times.

\section{Nomenclature}

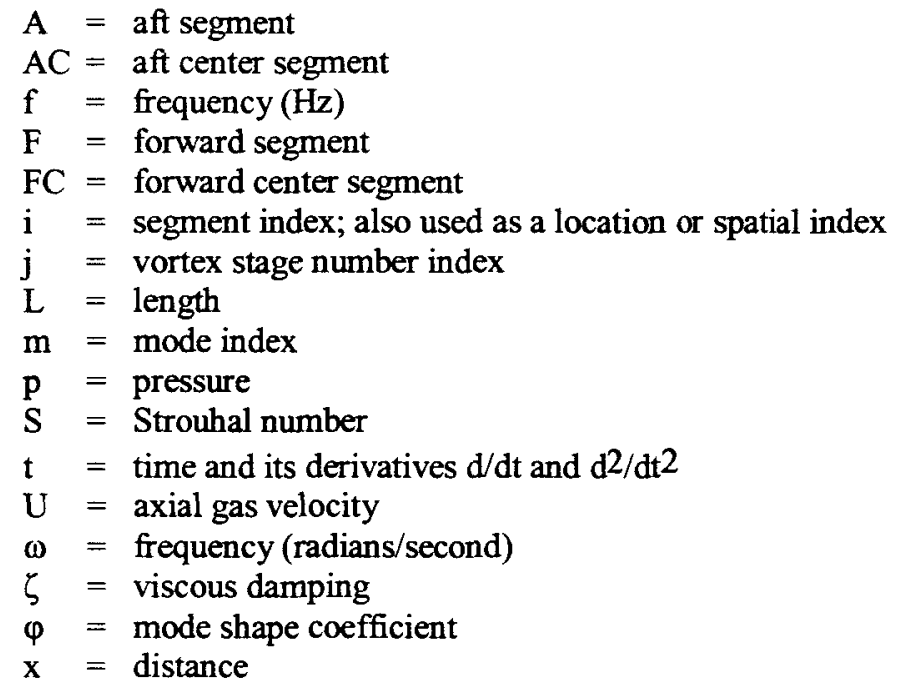

\section{Introduction}

Large segmented solid rocket motors have a history of exhibiting pressure oscillations with corresponding thrust oscillations. The Space Shuttle reusable solid rocket motor (RSRM) also exhibits low level pressure and thrust oscillations. Pressure and thrust oscillations were noted during the first ground test ${ }^{1}$ and have been monitored and studied since then.

Typical data from a recent RSRM static test is shown in Figs. 1 and 2. Measured head-end pressure typically contains quasi-sinusoidal signals associated with the internal longitudinal acoustic or organ pipe resonances of the motor (denoted as 1-L, 2-L, etc.). The 1-L and 2-L frequencies are near 15 and $29 \mathrm{~Hz}$, respectively, and vary only slightly during motor burn. These frequencies are shown in Fig. 1. Typically these oscillations start at about 40 seconds into motor burn.

\footnotetext{
* Technical Staff, Design and Analysis, P.O. Box 707, MS LF0, Associate Fellow

${ }^{+}$Senior Principal Engineer, Design and Analysis, P.O. Box 707, MS 252, Senior Member

${ }^{\ddagger}$ Engineer, Design and Analysis, P.O. Box 707, MS 252, Member

${ }^{\S}$ Engineer, Design and Analysis, P.O. Box 707, MS LF0

१Technical Manager, Design and Analysis, P.O. Box 707, MS LF0, Member
}

Copyright $(\mathcal{2} 2004$ by ATK Thiokol, an Alliant Techsystem affiliate.

Published by the American Institute of Aeronautics and Astronautics, Inc., with permission. 


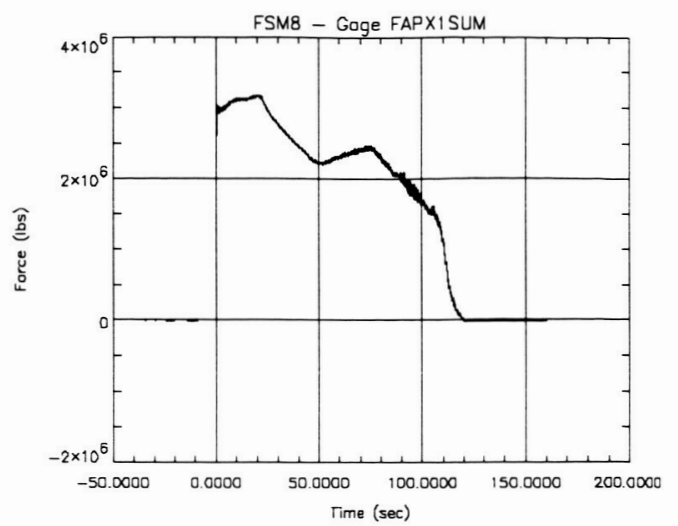

a) Time History: Measured Axial Thrust

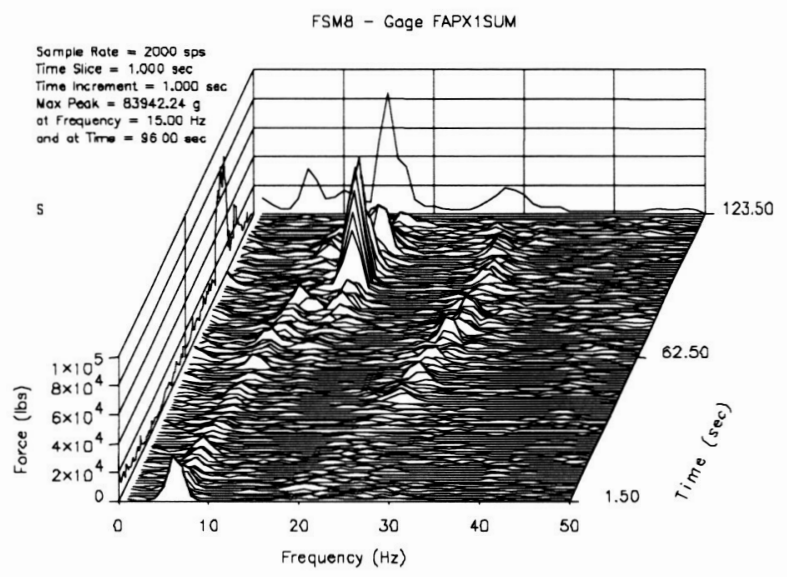

c) Waterfall Plot: Measured Dynamic Signal

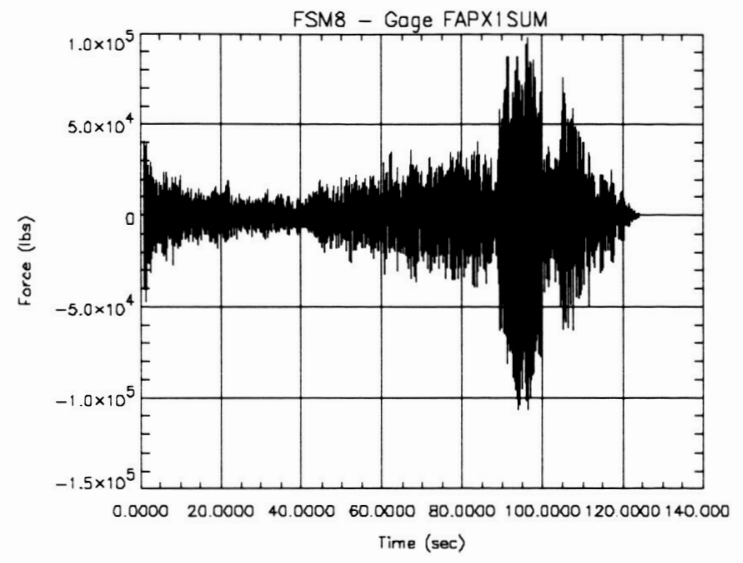

b) Time History: Measured Dynamic Signal

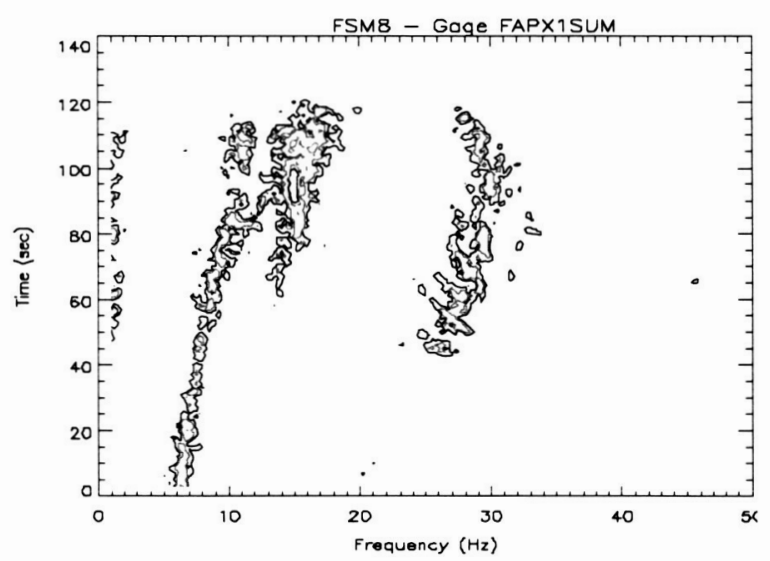

d) Contour Plot: Measured Dynamic Signal

Figure 2: Measured Axial Thrust Data from RSRM FSM-8 Static Test

Pressure oscillations in large, segmented, solid rocket motors are often the result of a vortex shedding phenomenon. Shearing action of the exhaust gases as the flow passes across internal segment slots and protruding inhibitor stubs causes vortices to form. Flatau presented the hypothesis that the shearing flow gives rise to vortices, which travel downstream and interact with a downstream baffle such as a protruding inhibitor stub. ${ }^{2,3}$ This action creates a sound or whistling noise. The frequency of the vortex shedding sound is a function of the axial gas velocity and the distance between inhibitors.

where

$$
\mathrm{f}_{\mathrm{ij}}=\mathrm{S}_{\mathrm{ij}} * \mathrm{U}_{\mathrm{i}} / \mathrm{L}_{\mathrm{i}}
$$

$i=$ segment number

$j=$ "stage number," which some have suggested is the number of vortices that fit in the space between upstream and downstream baffles. $j$ has some characteristics of a harmonic.

Vortex shedding frequencies decrease with motor burn time, since the axial gas velocity decreases with time as the propellant grains inner diameter increases.

Vortex shedding excitations have the potential to interact with the acoustic and structural modes of the motor (Fig. 3). 
Two approaches were applied to the problem of predicting and understanding pressure and thrust oscillations in a solid rocket motor. The first approach was a time domain simulation that numerically solved modal representations of a solid rocket motor's acoustic equations of motion. This simulation was anchored using an extensive database of foursegment RSRM measured data. The simulation was then extended to the five-segment engineering test motor (ETM-3). The second approach was a computational fluid dynamics

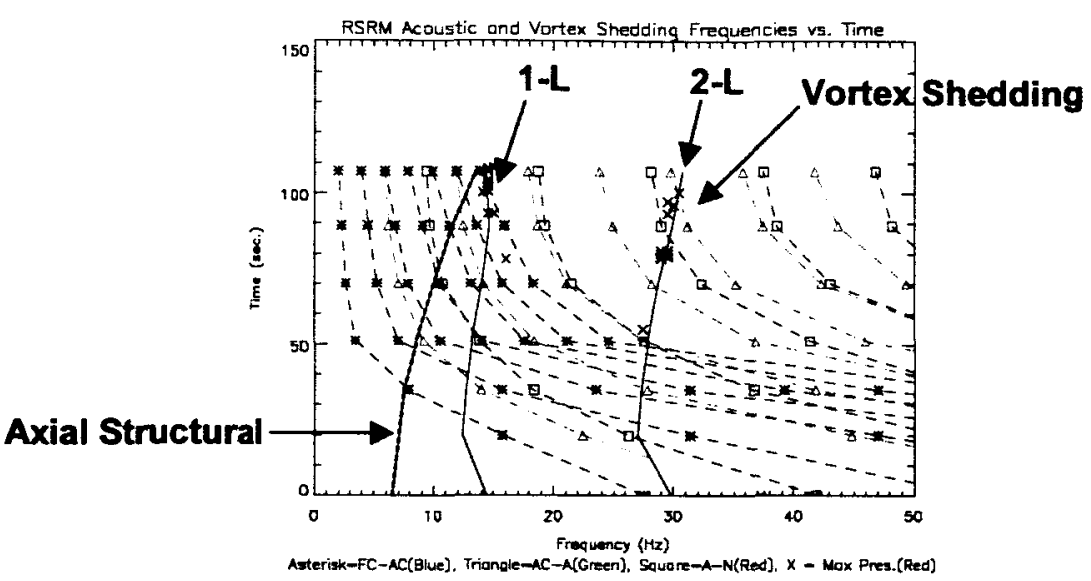

Figure 3: RSRM Acoustic, Structural, and Vortex Shedding Interactions

(CFD) two-dimensional (2-D) axi-symmetric large eddy simulation (LES) using the turbulence model option in FLUENT $^{\circledR}$. CFD models were developed at discrete motor burn times. Initially, the CFD effort was intended to better define some of the weakly defined parameters of the first approach described above. However, the CFD modeling effort showed great promise in fundamentally understanding and predicting the internal flow behavior of the RSRM, ETM-3, and other solid rocket motors.

\section{Simulating Vortex Shedding in the Time Domain}

The first approach was the development of a predictive procedure programmed on PV-Wave ${ }^{\circledR}$ software and based on numerically solving modal representations of a solid rocket motor's acoustic equations of motion at time intervals for the entire duration of motor burn. The first three longitudinal acoustic modes of the motors were implemented in the solution. Acoustic mode data for selected motor burn times for both motors were obtained from both the Standard Stability Prediction Program (SPP) and NASTRAN acoustic models.

Excitation to the system was assumed to be from sinusoidal sound (vortex shedding) sources located at each segment propellant slot and from distributed random (combustion noise) excitations along the length of the motor. The sinusoidal sound sources and their harmonics vary in both frequency and amplitude with motor burn time, and were derived from motor ballistic predictions. Strouhal number values for the harmonics were based on sub-scale cold flow simulations of the RSRM conducted by Flatau. ${ }^{2}$ The analytical procedure and model parameters such as sound source strengths, relative harmonic strengths, and acoustic damping were anchored using RSRM static test data.

The resulting simulated pressure oscillation time histories were then applied to NASTRAN structural models of the motor in the static test stand for discrete motor burn times. The resulting motor dynamic thrust and acceleration responses were calculated using Fast Fourier Transform (FFT) techniques to generate waterfall and contour plots of the simulated pressure, thrust, and acceleration time histories. The structural models were validated with pre-test and post-test modal surveys of the motor in the static test facility. Good correlation to measured static test data was obtained.

This new predictive technique was used to make worst-case, pre-test dynamic pressure and thrust oscillation predictions for the five-segment ETM-3 static test. This process bounded pre-test loads of the motor and test facility compared to structural capabilities.

The basic analytical approach was to solve the one-dimensional (1-D) partial differential equation of the acoustic system by assuming a separation of variables solution.

$$
p_{i}(x, t)=p_{i}(x) p_{i}(t)
$$

The dynamic response is the sum of the modal responses.

$$
p_{i}(x, t)=\Sigma_{m}\left(p_{i}\right)_{m}(x)\left(p_{i}\right)_{m}(t)
$$


Dynamic pressure excitation at the ith location was assumed to be of the form

$$
p_{i}(t)=\Sigma_{j} p_{i j} \sin \left(2 \pi f_{i j} t\right)
$$

where

$$
f_{i j}=S_{i j} U_{i} / L_{i} \text { and } j \text { denotes the stage number or the } j^{\text {th }} \text { harmonic. }
$$

The head-end $(x=H E)$ modal pressure $\left(p_{H E}\right)_{m}(t)$ resulting from the ith location excitation is obtained by numerically integrating the second-order single degree-of-freedom modal equation

$$
\mathrm{d} 2 / \mathrm{dt} 2\left(\mathrm{p}_{\mathrm{HE}, \mathrm{i}}\right)_{\mathrm{m}}+2 \zeta_{\mathrm{m}} \omega_{\mathrm{m}} \mathrm{d} / \mathrm{dt}\left(\mathrm{p}_{\mathrm{HE}, \mathrm{i}}\right)_{\mathrm{m}}+\omega_{\mathrm{m}}^{2}\left(\mathrm{p}_{\mathrm{HE}, \mathrm{i}}\right)_{\mathrm{m}}=\mathrm{p}_{\mathrm{i}}(\mathrm{t})
$$

This yields $\left(\mathrm{p}_{\mathrm{HE}, \mathrm{i}}\right)_{\mathrm{m}}(\mathrm{t})$

The mode shape ratio between the ith location and the head-end is $\left(\mathrm{p}_{\mathrm{HE}, \mathrm{i}}\right)_{\mathrm{m}}$

$$
\left(\mathrm{p}_{\mathrm{i}}\right)_{\mathrm{m}}(\mathrm{x})=\left(\mathrm{p}_{\mathrm{HE}, \mathrm{i}}\right)_{\mathrm{m}}=\left(\varphi_{\mathrm{HE}} / \varphi_{\mathrm{i}}\right)_{\mathrm{m}}
$$

Therefore,

$$
P_{H E, i}(t)=\Sigma_{m}\left(\varphi_{H E} / \varphi_{i}\right)_{m}\left(p_{H E, i}\right)_{m}(t)
$$

For multiple excitation locations, linear superposition was used

$$
\mathrm{p}_{\mathrm{HE}}(\mathrm{t})=\Sigma_{\mathrm{i}} \mathrm{P}_{\mathrm{HE}, \mathrm{i}}(\mathrm{t})
$$

Random excitations were applied to simulate the combustion noise effects seen in test data

$$
p_{i}(t)=p_{i} f(t)_{\text {Random }}
$$

This procedure was programmed using PV-Wave ${ }^{\circledR}$ software. The resulting $\mathrm{p}_{\mathrm{HE}}$ time history was processed as if it were measured data.

Numerous assumptions and weakly defined parameters are involved in this simulation. The RSRM pressure oscillation observed behavior was used to refine the assumptions and define the various simulation parameters.

In the vortex shedding frequency equation Eq. (1), $S_{j}$ was assumed to $=0.85 * j$ for $j=1-4$ ( $j>4$ were not observed in RSRM test data). Flatau also used $\mathrm{j}=1-4$ with $\mathrm{S}_{1}=0.9, \mathrm{~S}_{2}=1.6, \mathrm{~S}_{3}=2.5, \mathrm{~S}_{4}=3.5{ }^{2} \mathrm{U}_{\mathrm{i}}$ are 1-D port velocities at the slots obtained from 1-D ballistic runs (Fig. 4).

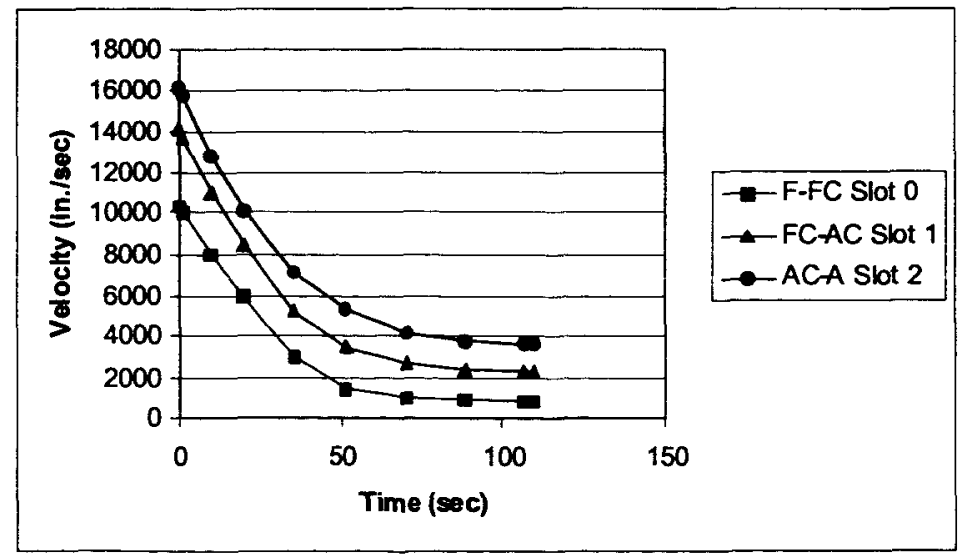

Figure 4: RSRM Velocity vs. Time 
$L_{i}$ are distances between the slots (or aft slot to nozzle length for the aft segment). For RSRM: $L_{1}=L_{2}=L_{3}=320$ in., $\mathrm{L}_{4}=330 \mathrm{in}$.

Vortex sound locations were assumed to be at the downstream slots (or nozzle for aft segment) consistent with the hypothesis of hole-tone generated sound. The RSRM has three such locations: $1=$ FC-AC, 2 = AC-A, and $3=$ A-N (Fig. 5).

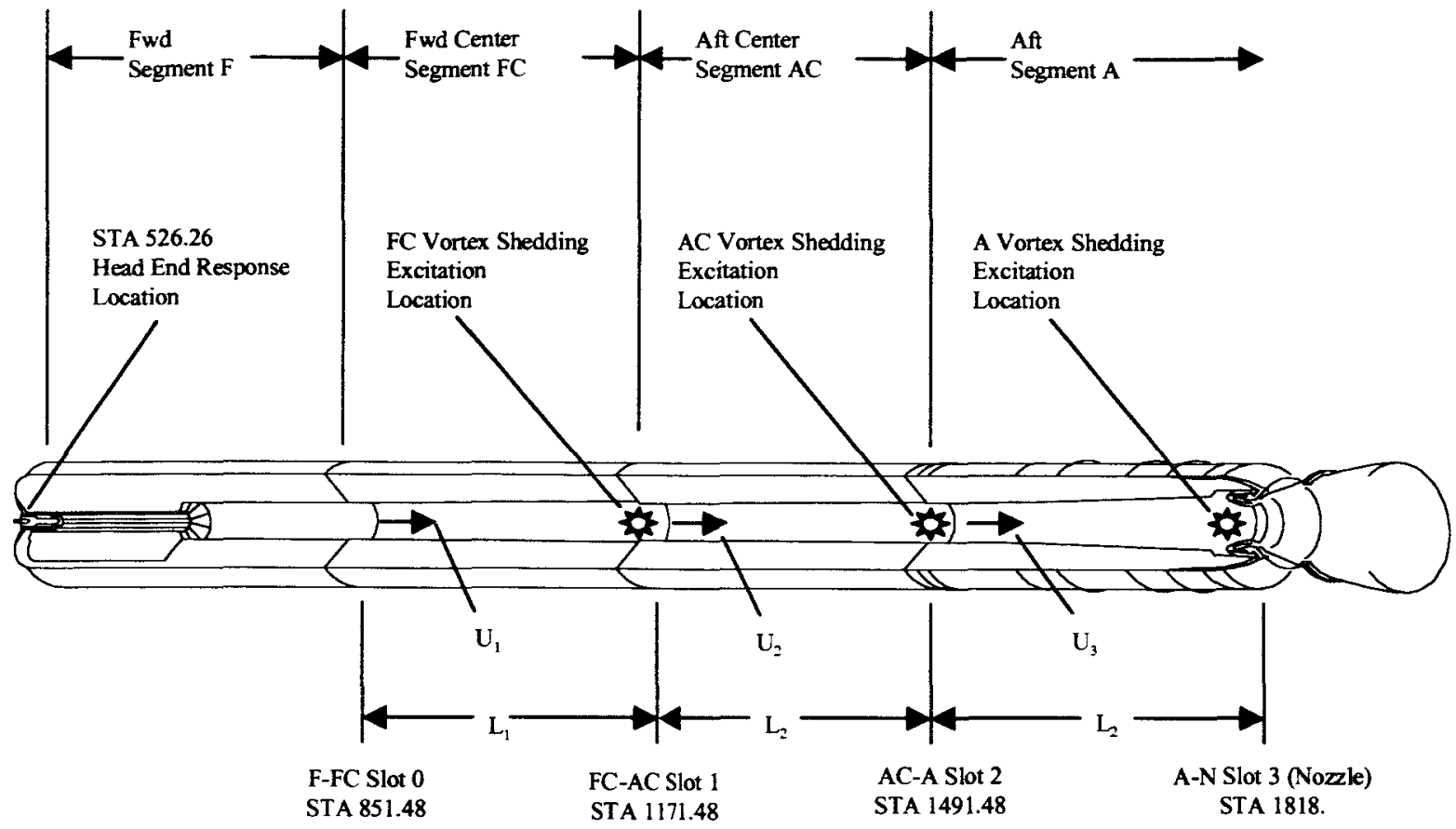

Figure 5: RSRM Vortex Sound Locations

The vortex sound pressure strength at each of the $i^{\text {th }}$ slots is assumed to be $\left(p_{s}\right)_{i}=\alpha_{i}\left(1 / 2 \rho_{i} U_{i}^{2}\right)$, where $\alpha_{1}$ was obtained by matching RSRM data, $\left.\alpha_{2}=\alpha_{1}\left(\mathrm{U}_{2}\right) / \mathrm{U}_{1}\right)$, and $\left.\alpha_{3}=\alpha_{1}\left(\mathrm{U}_{3}\right) / \mathrm{U}_{1}\right)$. This eliminates arbitrarily selecting three parameters. From RSRM data, it was noticed that the apparent vortex sound pressure strengths were approximately related by the above velocity ratios. Weighting factors on stage numbers and on time were applied as suggested by RSRM measured data.

The random sound pressure locations were distributed along the length of the motor. For the $i^{\text {th }}$ excitation location, $\left(p_{1}\right)_{i}=\left[\beta_{1}\left(1 / 2 \rho_{i} U_{i}^{2}\right)+\beta_{2} A_{i}\right]$, where $\beta_{1}$ and $\beta_{2}$ were obtained by matching RSRM data and $\left(1 / 2 \rho_{i} U_{i}{ }^{2}\right)=$ mid-segment dynamic pressure and $A_{i}=$ mid-segment surface area. $U_{i}$ and $A_{i}$ vary with time. The two factors comprising $p_{T}$ are an attempt to simulate the random sound originating both from aerodynamic flow (decreases with decreasing port velocity) and from propellant combustion (increases/decreases with increasing/decreasing burn area). A random time-weighting function was also applied as suggested by RSRM measured data.

The longitudinal internal acoustic modes of the RSRM have been extensively studied throughout the program. Figure 6 summarizes some of this history. 

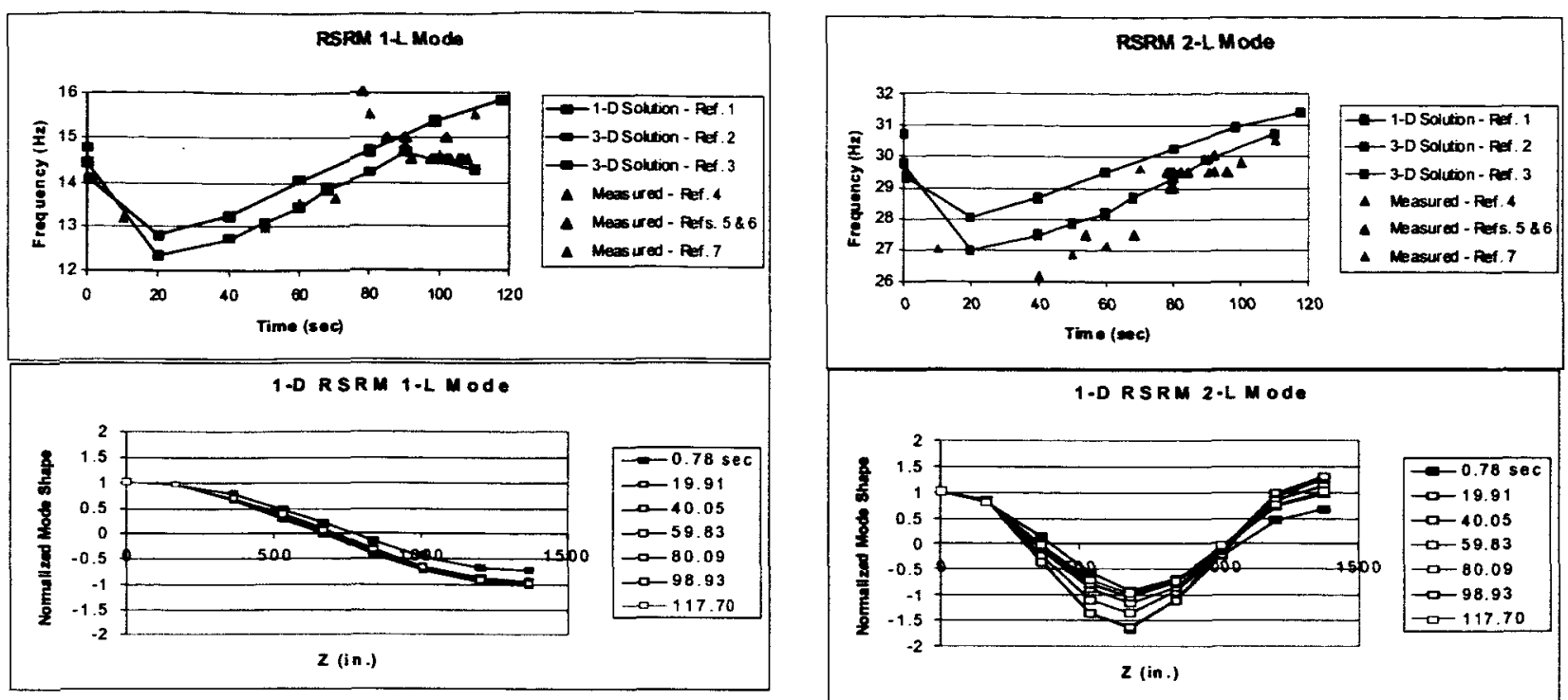

Figure 6: RSRM Longitudinal Acoustic Modal Characteristics

For the RSRM simulation, acoustic natural frequencies versus burn time were obtained from a three-dimensional (3-D) acoustic model followed by curve-fitting versus burn time to generate a continuous function.

RSRM mode shapes versus time were obtained from 1-D SPP runs. Mode shape coefficients at discrete burn times were curve-fit to create a continuous mode shape variation with burn time.

Acoustic damping was also assumed as a function of time and reflects a variation with gas density as motor pressure changes. Damping values were anchored to RSRM data.

The motor in its test stand has numerous natural frequencies in the frequency range of the acoustic modes. Most are motor bending and/or torsional in nature and also involve circumferential wave or case shell motion. Several structural modes involve significant axial motion and are susceptible to being excited by longitudinal acoustic excitations. Numerous analytical models of the motor in its test stand have been developed over the years. Some of these models are finite element models of very high fidelity and represent the motor at several discrete burn times (Fig. 7). In addition, several modal surveys have been conducted to provide validation of analytical structural models and to provide modal damping information.

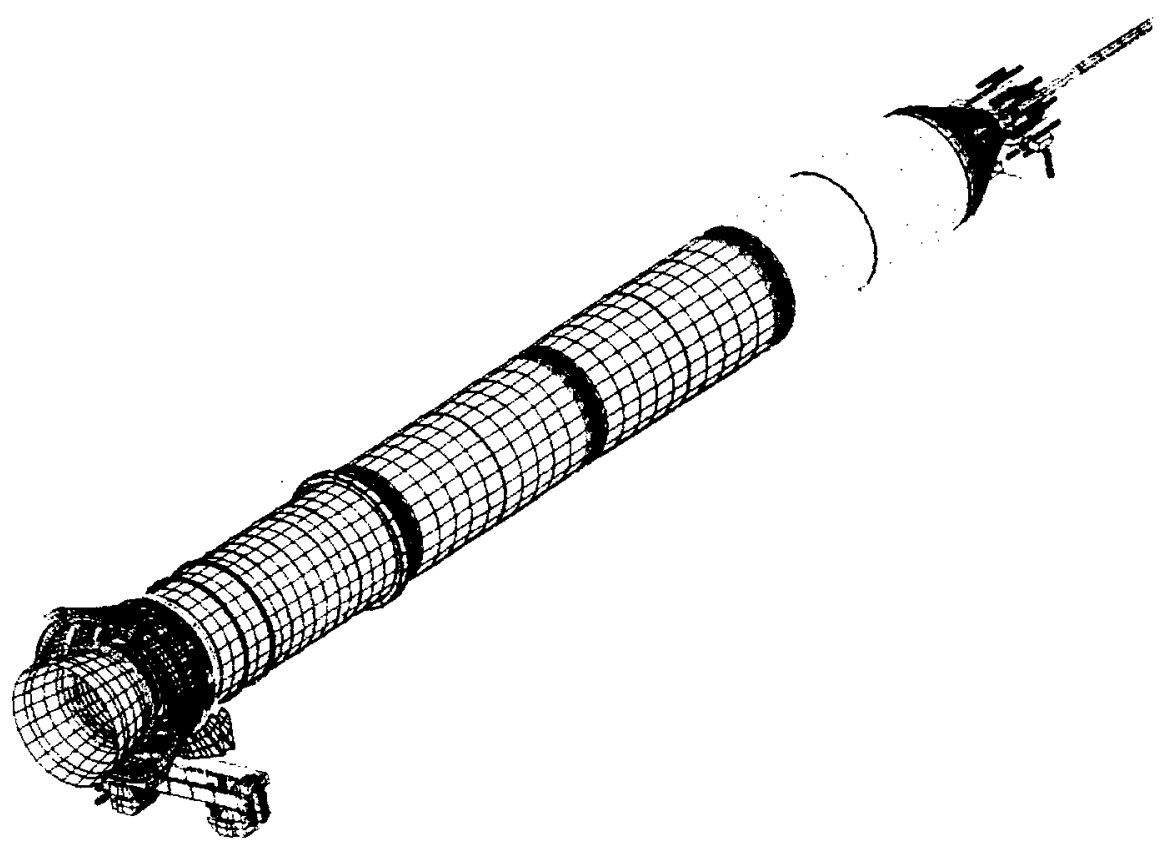

Figure 7: Structural Finite Element Model of RSRM in T-97 Test Stand 
The governing equations of motion were programmed and numerically integrated using PV-Wave ${ }^{\circledR}$ software. A time history of head-end pressure was generated at 0.001-second time intervals. The resulting data were processed as if it were actual pressure data. The results are shown in Fig. 8; compare to Fig. 1. Although the amplitude scales are slightly different, the simulation is similar to the measured data.

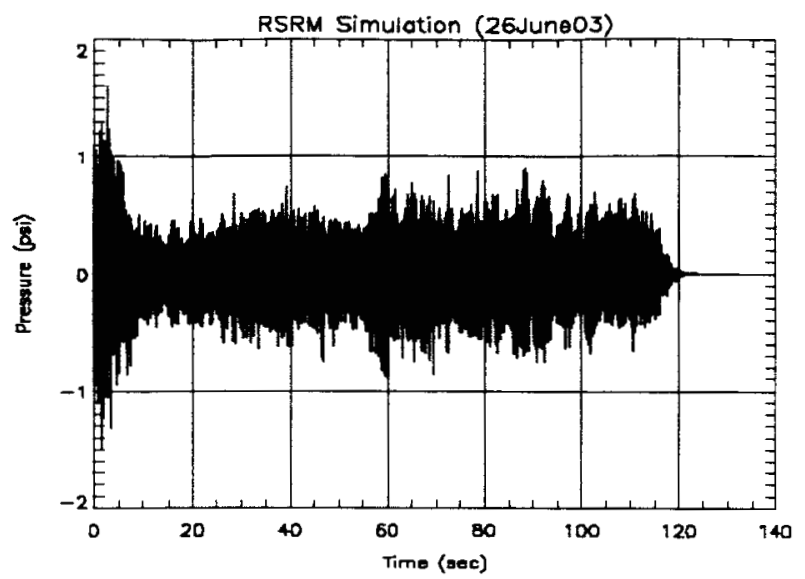

a) Time Historv: Simulated Dvnamic Signal

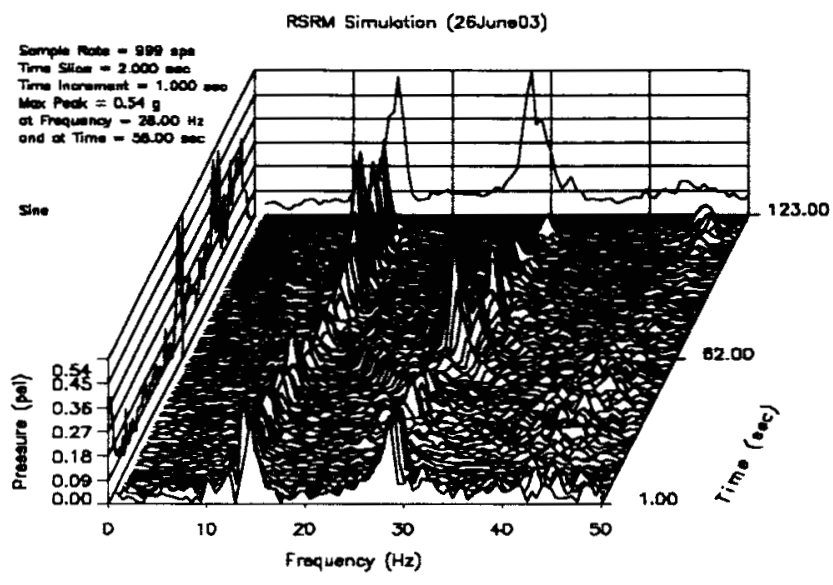

b) Waterfall Plot: Simulated Dynamic Signal

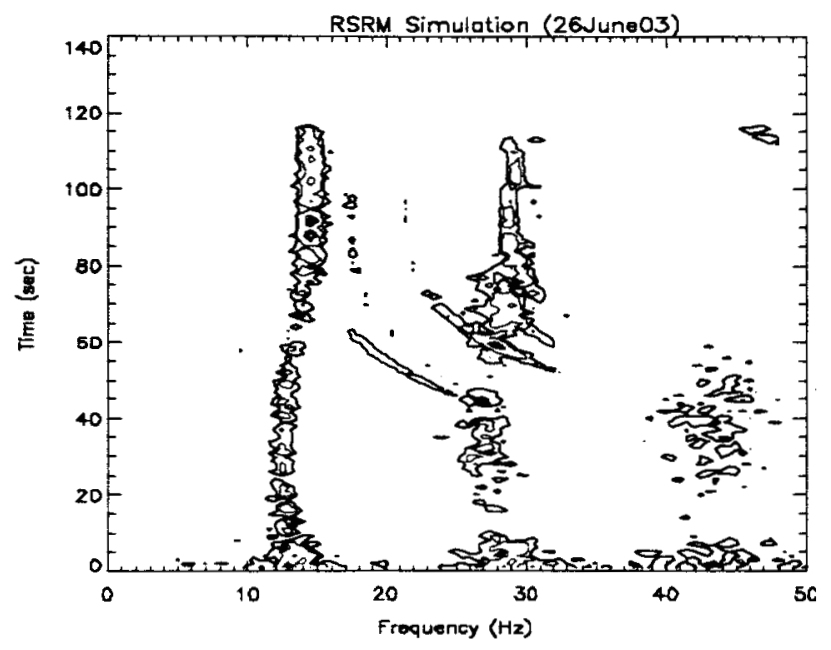

c) Contour Plot: Simulated Dynamic Signal

Figure 8: Simulated RSRM Head-End Pressure 
In a similar fashion, the aft-end pressure time history was also simulated, and the head-end and aft-end pressure time histories were applied to NASTRAN structural models at several discrete motor burn times. The simulated load in the axial load cell was output for each discrete burn time model. These discrete load time histories were appended to produce a continuous time history, which was processed as if it were measured data. The results are shown in Fig. 9; compare to Fig. 2.

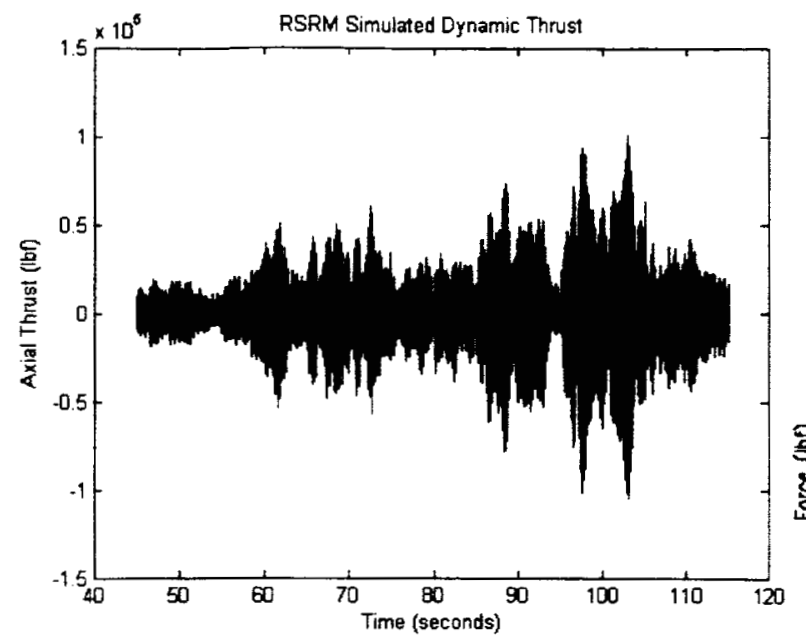

a) Time History: Simulated Dynamic Signal

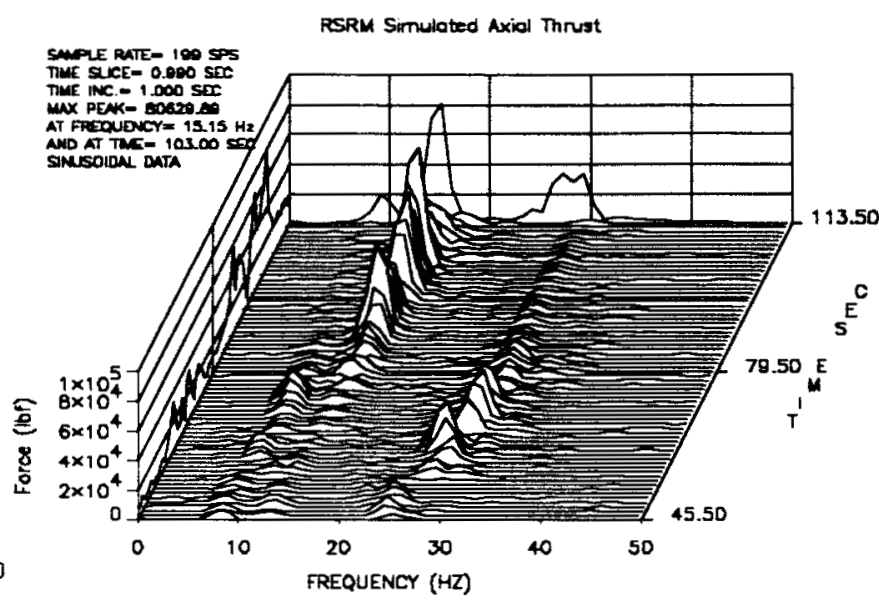

b) Waterfall Plot: Simulated Dynamic Signal

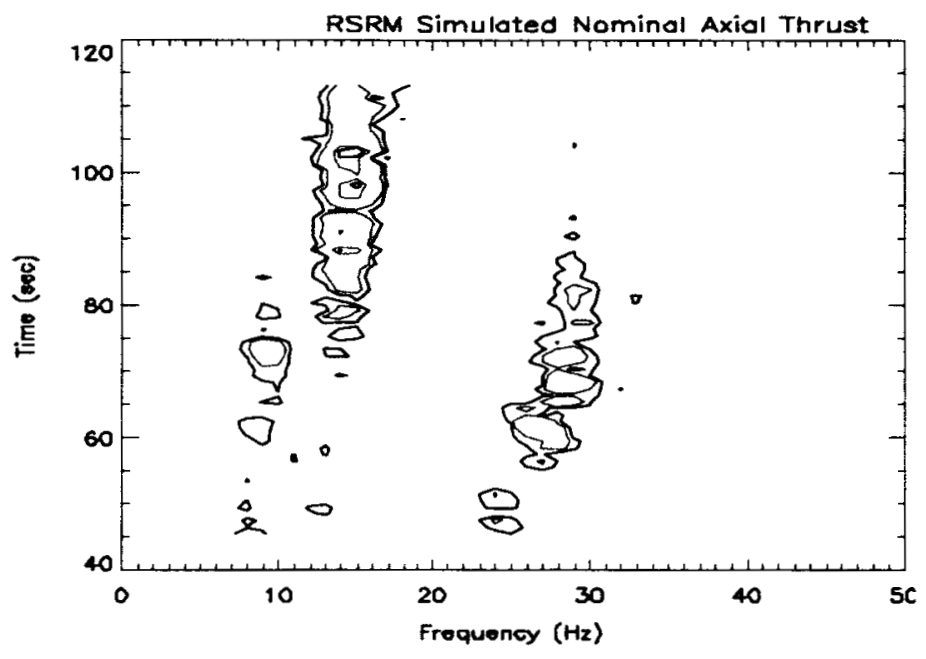

c) Contour Plot: Simulated Dynamic Signal

Figure 9: Simulated RSRM Axial Thrust 
This same simulation procedure was applied to the five-segment ETM-3 motor as a predictive tool to bound pressure and thrust oscillation amplitudes, frequencies, and occurrence times. Vortex shedding frequencies were adversely shifted to create several worst-case conditions. Figures 10 and 11 present worst-case 1-L pressure and thrust simulations.

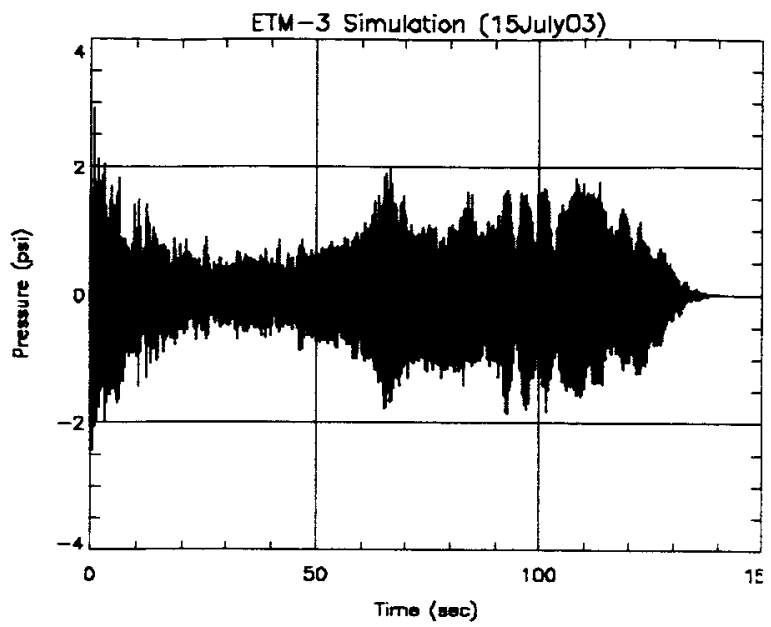

a) Time History: Simulated Dynamic Signal

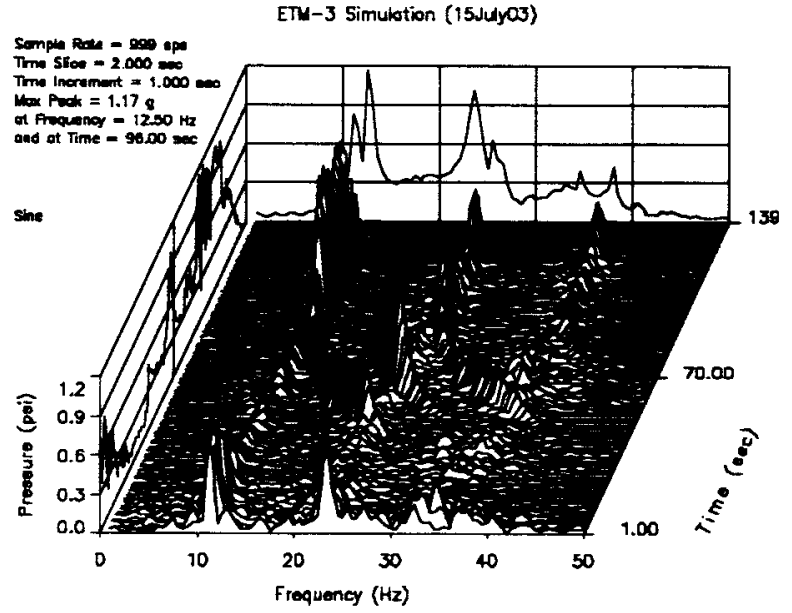

b) Waterfall Plot: Simulated Dynamic Signal

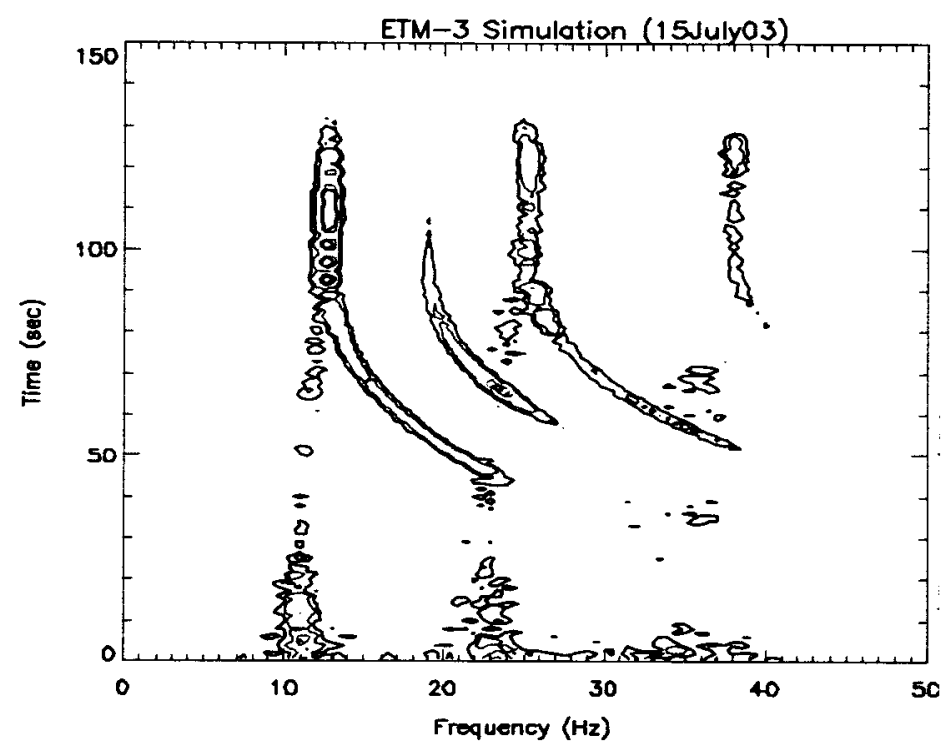

c) Contour Plot: Simulated Dynamic Signal

Figure 10: Simulated ETM-3 Worst-Case 1-L Head-End Pressure 


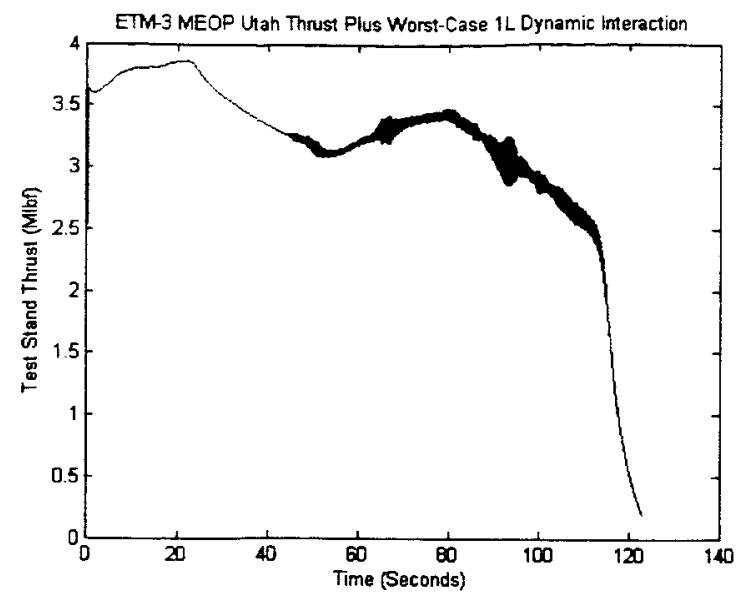

a) Time History: Simulated Axial Thrust

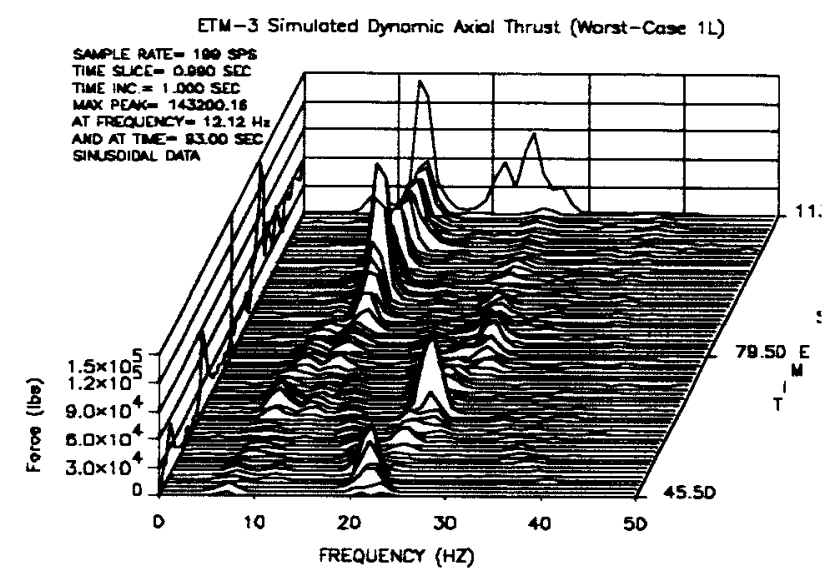

b) Waterfall Plot: Simulated Dynamic Signal

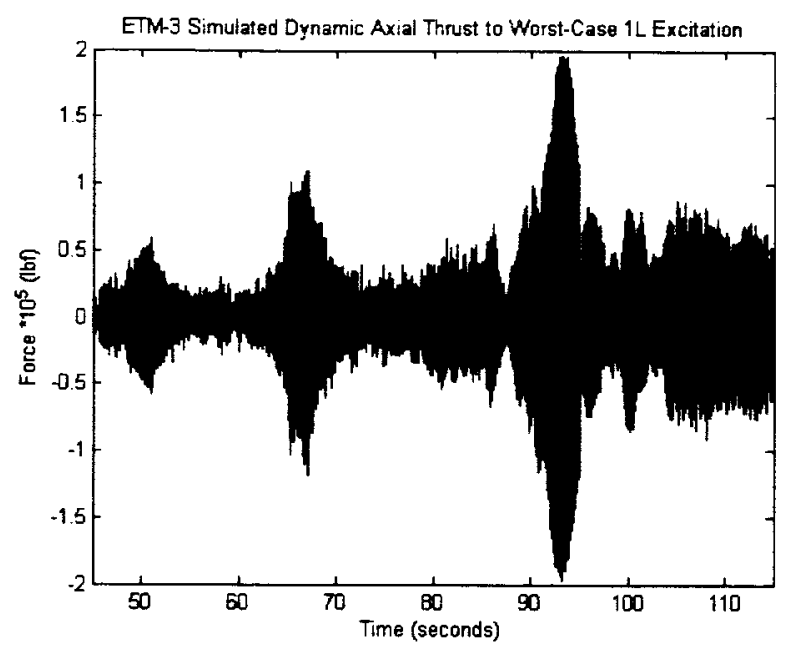

b) Time History: Simulated Dynamic Signal

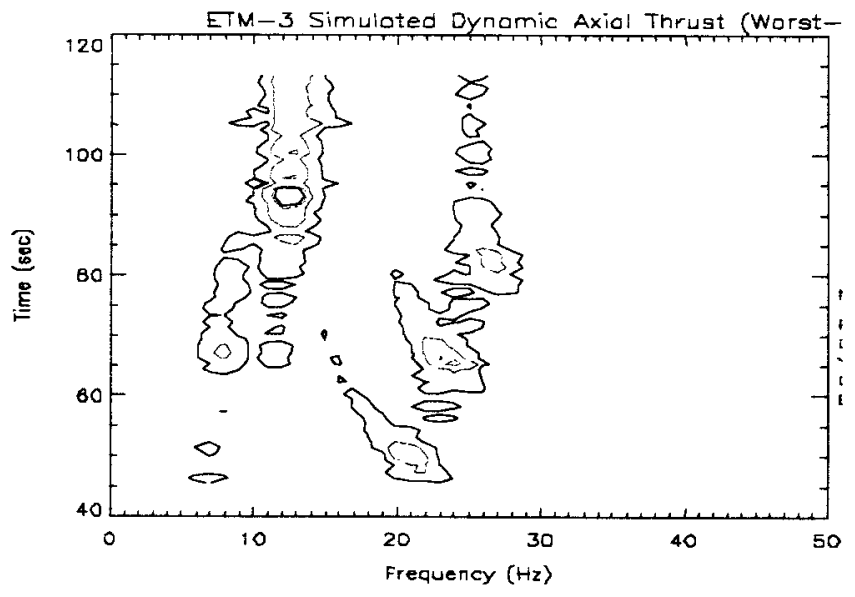

c) Contour Plot: Simulated Dynamic Signal

Figure 11: Simulated ETM-3 Axial Thrust for Worst-Case 1-L Pressure 


\section{Computational Fluid Dynamics Simulations}

The second approach was to use the 2-D axi-symmetric LES turbulence model option in FLUENT $^{\circledR}$ at three different motor burn times. Although, the model does not allow for 3-D vortex stretching, it does allow the entire motor to be efficiently modeled with all the inhibitor stubs, with a reasonable number of grid cells and in a reasonable amount of computer time. The inhibitor stubs were modeled using the best information available for the height, thickness, and bending geometry.

Noting that a 3-D LES model had been successfully used for the French Cold Flow Test, a 2-D planar LES model using FLUENT ${ }^{\circledR}$ was constructed for the same cold flow simulation. ${ }^{4,5,6}$ Results of the FLUENT ${ }^{\circledR}$ model were comparable to the previous work.

The LES turbulence model is an unsteady flow model using a small time-step on the order of 5E-05 seconds. The size of the model is on the order of the size of a steady-state Reynolds Averaged Navier-Stokes (RANS) model or about 80,000 cells. Within the 2-D axi-symmetric option, the LES model uses the turbulent standard wall function. The FLUENT ${ }^{\mathbb{Q}}$ solution controls were set as second-order for pressure and density. The central differencing scheme was recommended for both the momentum and energy solver. However, it was found that the LES model results looked reasonable with the power-law for the energy solver and it ran faster with better convergence. The sub-gridscale model used the Smagorinsky-Lilly option.

The steady-state RANS model included the propellant burn-rate power-law as a function of local pressure. However, this model was turned off when the LES model was turned on. Otherwise, the LES model took too long to converge. Even though, the burn-rate power-law is absent in the LES model, some of the effects are partially accounted for, because the mass addition does vary down the bore approximately with the mean pressure drop. It was found that after the LES model was activated, the model would have a slow transient for about 1.5 seconds before settling down to a quasi-steady pattern in which pressure oscillations were occurring about a mean pressure. After the slow transient decay, the pressure monitor data could be used for the FFT and contour variables could be used for plotting internal motor descriptions. All of the FLUENT ${ }^{\circledR}$ runs used the single-phase model or a homogeneous gas without discrete particles.

Figure 12 is a full view contour plot of the vorticity for the RSRM and ETM-3. Careful inspection shows that the vortices from the forward inhibitor, which is the longest, remain the most distinct as they move down the bore. Because of the length of the forward inhibitor, these vortices are produced close to the motor centerline. Since these vortices travel the full length of the bore, they have time to migrate closer to the centerline and tend to dissipate by the time they reach the nozzle nose.

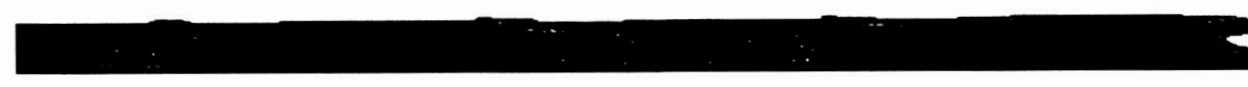

a) RSRM at 100 Seconds

b) ETM-3 at 100 Seconds

Figure 12: RSRM and ETM-3 Vorticity Contour Plots 
A close-up view of the RSRM and ETM-3 forward inhibitor stub is shown in Figs. 13 and 14, respectively. Inspection shows that the vortices from the forward inhibitor do not interact significantly with the wall instability layer. Movies made from these still plots clearly show that the vortices rapidly leaving the inhibitor stub tip tend to pair and revolve around each other until they coalesce into one larger but weaker vortex traveling downstream toward the nozzle. The revolution of two vortices with like rotation about a common origin is in keeping with the classical inviscid analytical solution of two vortex filaments with like spin. ${ }^{7,8,9}$

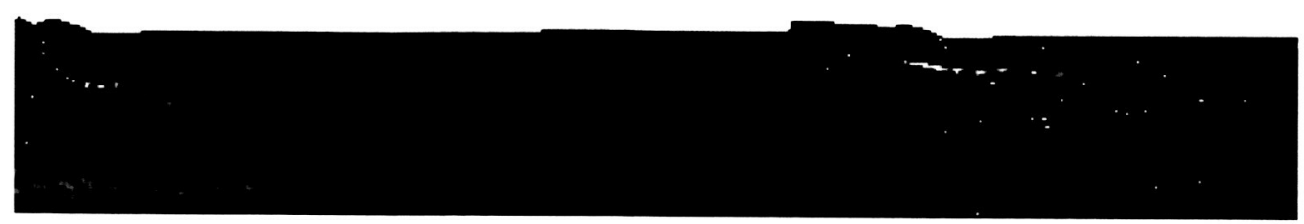

Figure 13: RSRM Forward Inhibitor Vorticity View at 100 Seconds

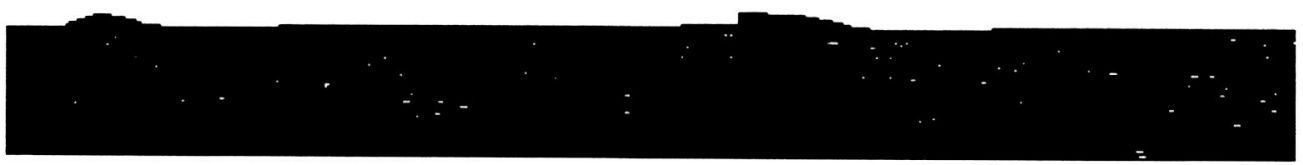

Figure 14: ETM-3 Forward Inhibitor Vorticity View at 100 Seconds

The general explanation for the phenomena of the sustained vortex shedding pressure oscillations is that large vortex structures interact with the nozzle nose causing a pressure wave to move upstream, which excites the 1-L acoustic mode of the motor. Flandro presented an early description of this process for solid rocket motors. ${ }^{10}$ The general topic of flow structure impingement on solid surfaces is very wide ranging. Flandro also presented a good survey of this subject. ${ }^{11}$ Another source of sound was treated analytically by Rockwell, which shows that vortices moving around obstacles can produce acoustic waves. ${ }^{11}$

Since the interaction of vortex structures with the nozzle is important, a sequence of close-up views of the RSRM center and aft inhibitor stubs are shown in Fig. 58.

Each inset in Fig. 15 has been given the label of Frame No. 1 to Frame No. 6. Each frame is 0.012 seconds apart, so that six frames constitute about one cycle of the first harmonic. These are just some of the frames to make one movie. Each frame shown here actually represents every fourth frame in the movie. The movie goes for several cycles so that 109 frames are used.

Figure 15 shows the very active center inhibitor stub is rapidly shedding vortices that interact with the downstream wall instability layer. Basically, there are three different types of vorticity regions listed as follows: 1) the wall instability layer, 2) the vortices shedding from inhibitor stubs, and 3) vortices shed from flow over propellant segment cavities. All three types have also been documented in literature. ${ }^{13,14,15}$ 
It is interesting to track the large vorticity region (magenta color) just upstream of the aft inhibitor and another large vorticity region midway between the aft inhibitor and the nozzle nose. The second region is just down stream of a small low vorticity (light blue) region. Proceeding to Frame No. 6 it can be seen that the first vorticity structure is stretched and pulled over the aft inhibitor stub, while the second structure is stretched and pulled towards the nozzle nose. The latter structure appears to either slip out and over the nozzle nose and/or breaks up at the nozzle nose. All the time that these two respective structures are moving downstream, one can observe new structures arriving from upstream to replace them. Clearly, the process has a lot of noise and/or velocity fluctuations, but some general trends are evident.

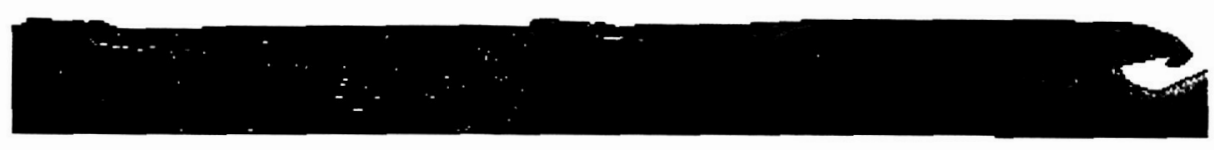

Frame No. 1 Run Time $=\mathbf{2} .4835$ seconds

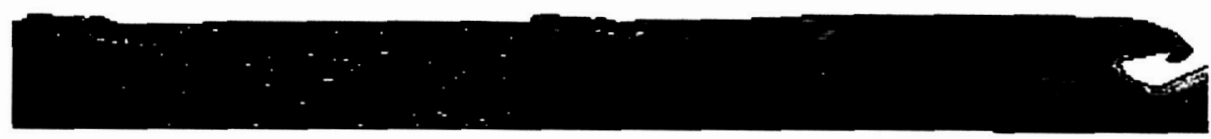

Frame No. 2 Run Time $=\mathbf{2} .4955$ seconds

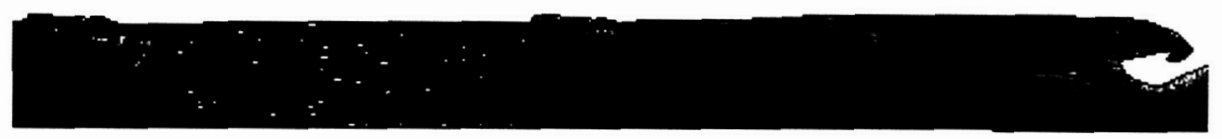

Frame No. 3 Run Time $=2.5075$ seconds

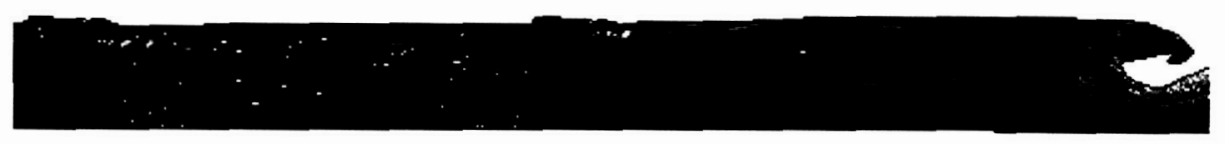

Frame No. 4 Run Time $=\mathbf{2} .5195$ seconds

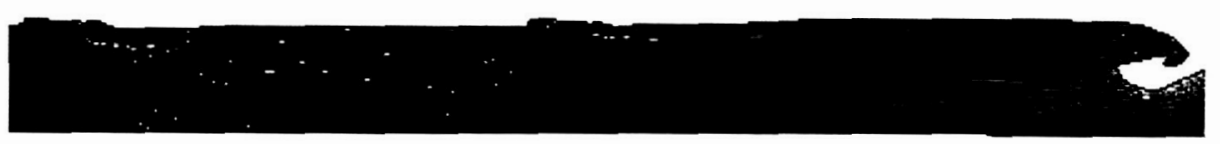

Frame No. 5 Run Time $=\mathbf{2} . \mathbf{5 3 1 5}$ seconds

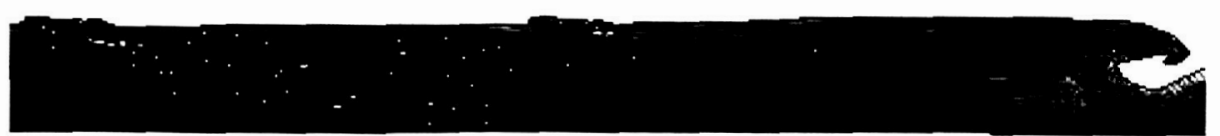

Frame No. 6 Run Time $=\mathbf{2} .5435$ seconds

Figure 15: RSRM Center and Aft Inhibitor Region Vorticity at 100-Second Burn Time 
Figure 16 shows six frames for the internal motor pressure that correspond to the same times as the vorticity Fig. 18. These frames were constructed by subtracting out the mean pressure drop as a function of axial distance down the length of the motor. So the pressure shown is the fluctuation about the mean pressure for a given axial distance. The mean pressure drop down the RSRM bore at 100 seconds is about 7 psi, which is larger than the fluctuations. Close inspection of Fig. 16 reveals small low-pressure eddy centers (small green dots) traveling downstream of the center inhibitor. Likewise, a low-pressure area (large blue area) appears in the aft segment, but never in the head-end in all the figures. This is because the opportunity for large vorticity roll-up exists in the aft-end, but not in the headend.

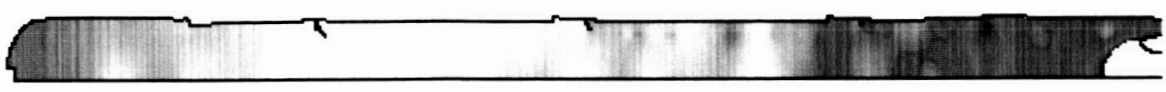

Frame No. 1 Run Time $=\mathbf{2 . 4 8 3 5}$ seconds

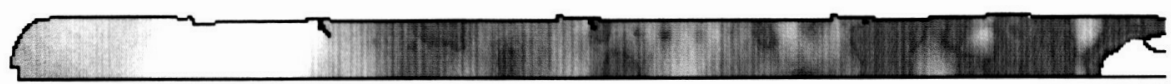

Frame No. 2 Run Time $=\mathbf{2 . 4 9 5 5}$ seconds

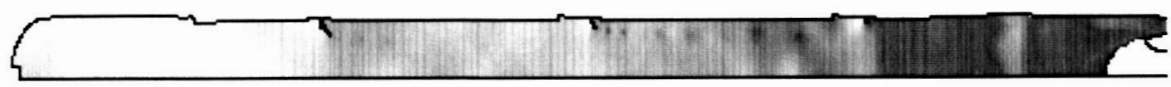

Frame No. 3 Run Time $=\mathbf{2 . 5 0 7 5}$ seconds

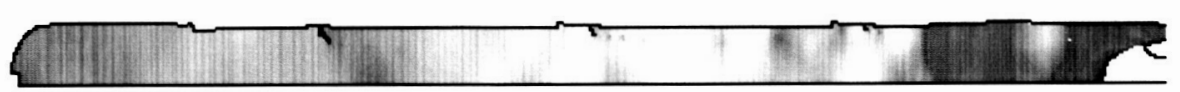

Frame No. 4 Run Time $=\mathbf{2 . 5 1 9 5}$ seconds

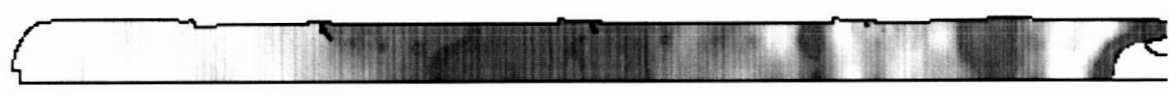

Frame No. 5 Run Time $=\mathbf{2 . 5 3 1 5}$ seconds

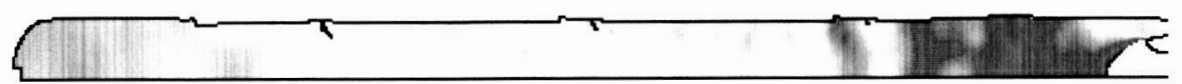

Frame No. 6 Run Time $=\mathbf{2} .5435$ seconds

Figure 16: RSRM Center and Aft Inhibitor Region Pressure Contour at 100-Second Burn Time 


\section{Conclusion}

The complex interactions between internal motor pressure oscillations resulting from vortex shedding, the motor's internal acoustic modes, and the motor's structural vibration modes were assessed for RSRM and the ETM3 motors. Two approaches were applied to this problem as previously described. Figure 17 presents a comparison of the pressure amplitude results from both approaches as compared to measured RSRM data at the 100-second burn time. PNCAC001 measured the full pressure (quasi-steady-state and dynamic signal) and PNCAC024 measured only the dynamic signal. Results compared reasonably well considering the numerous assumptions involved in the two approaches. Figure 18 compares results for the ETM-3 motor at 100 seconds.

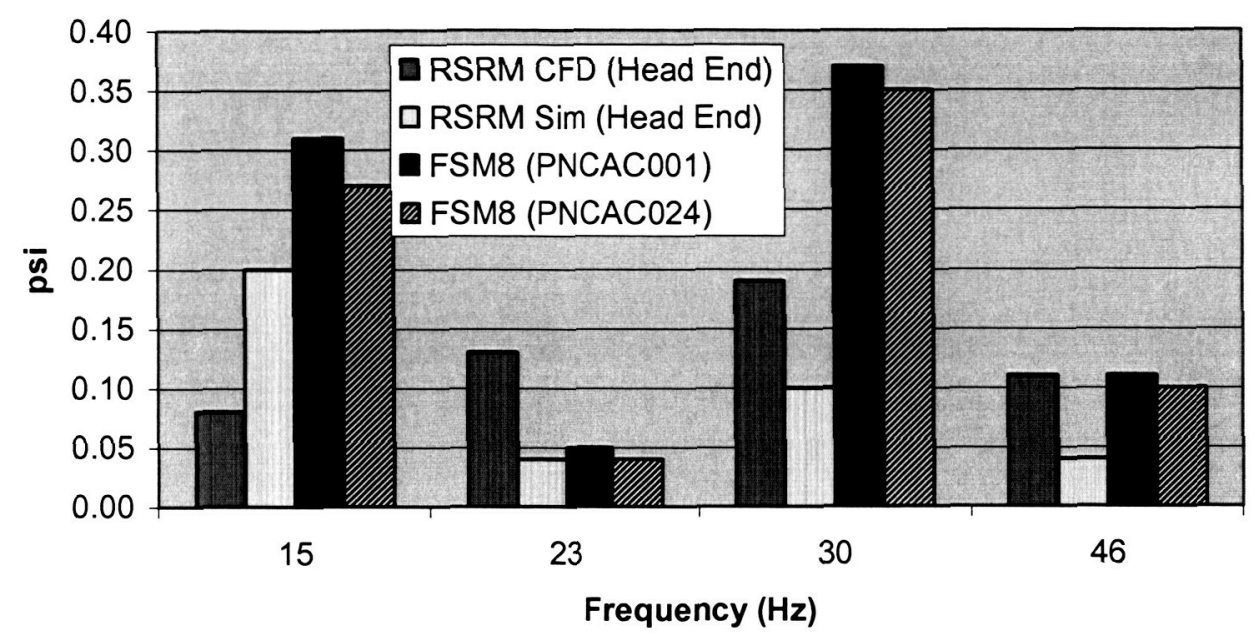

Figure 17: Comparison of RSRM Head-End Pressure Results at 100-Second Burn Time

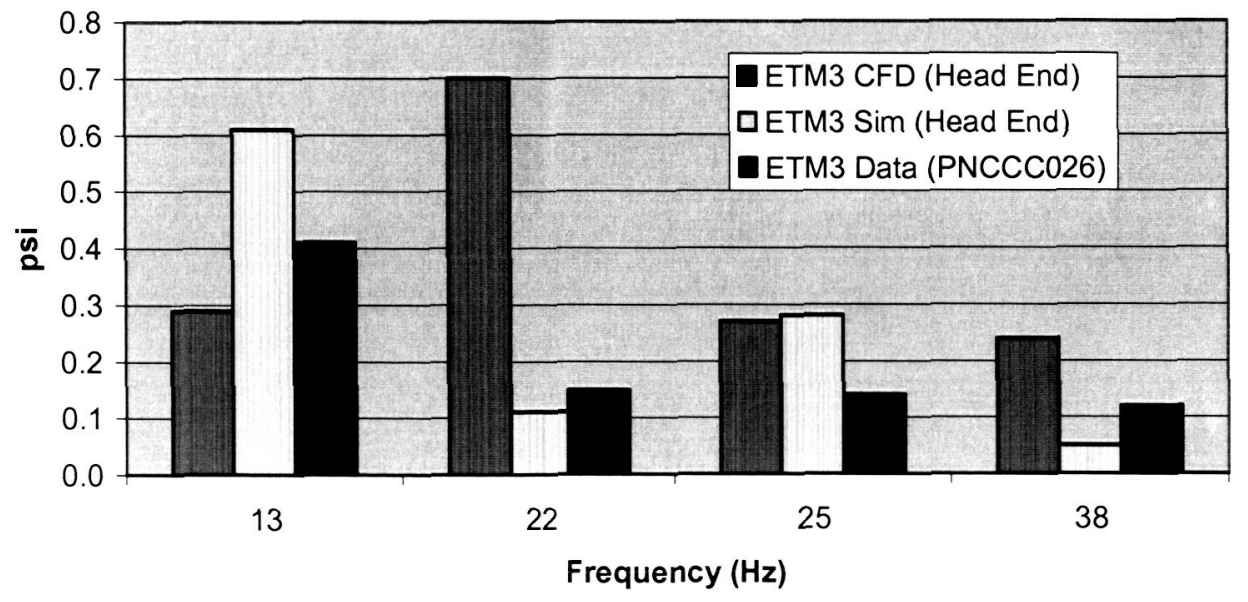

Figure 18: Comparison of ETM-3 Head-End Pressure Results at 100-Second Burn Time 


\section{Acknowledgements}

The authors would like to thank the following individuals: John Townsend, Tom Nesman and Frank Bugg of the NASA Marshall Space Center for their encouragement and critique, Thomas Scheidegger at Fluent ${ }^{\text {B }}$ for his excellent and timely advice in the CFD modeling efforts, and Professor Najjar at the University of Illinois for his helpful advice on CFD/turbulence modeling.

\section{References}

${ }^{1}$ Mason, D. R., Folkman, S. L., and Behring, M.A., "Thrust Oscillation of the Space Shuttle Solid Rocket Booster Motor During Static Tests," AIAA 15 th Joint Propulsion Conference, AIAA 79-1138, Las Vegas, NV, 1979.

${ }^{2}$ Flatau, A. B., and Van Moorhem, W. K., "Prediction of Vortex Shedding Responses in Segmented Solid Rocket Motors," AIAA 90-2073, 1990.

${ }^{3}$ Flatau, A. B., and Van Moorhem, W. K., "Cold-flow Investigation of Vortex-shedding Induced Sound Amplitude Variations," $33^{\text {rd }}$ Aerospace Sciences Meeting and Exhibit, AlAA 95-0605, Reno, NV, 1995.

${ }^{4}$ Vetel, J., Plourde, F., and Doan-Kim, S., "Experimental and Numerical Characterizations of Unstable Sources in a Solid Rocket Motor," $37^{\text {th }}$ Joint Propulsion Conference, AIAA 2001-3866, Salt Lake City, UT, July 2001.

${ }^{5}$ Vetel, J., Plourde, F., Doan-Kim, S., and Guery, J. F., "Numerical Simulations of Wall and Shear Layer Instabilities in Cold Flow Setup," Journal of Propulsion and Power, Vol. 19, No. 2, March-April 2003, pp. 297-306.

${ }^{6}$ Plourde, F., Najjar, F.M., Vetel, J., Wasistho, B., Doan-Kim, S., and Balachandar, S., "Numerical Simulations of Wall and Shear-Layer Instabilities in a Cold Flow Set-up," $39^{\text {th }}$ Joint Propulsion Conference, AIAA 2003-4674, Huntsville, AL, July 2003.

${ }^{7}$ Robertson, J. M., Hydrodynamics in Theory and Application, Prentice-Hall, Inc., Englewood Cliffs, NJ, 1965, p.116, 126.

${ }^{8}$ Milne-Thomson, L. M., Theoretical Hydrodynamics, $4^{\text {th }}$ Edition, Macmillian \& Co., NY, 1960, pp. 356, 569.

${ }^{9}$ Lamb, H., Hydrodynamics, $6^{\text {th }}$ Edition, Dover Publications, N.Y., 1945, pp. 221, 590-592.

${ }^{10}$ Flandro, G. A., "Vortex Driving Mechanism in Oscillatory Rocket Flows," Journal of Propulsion, Vol. 2, No. 3, May-June 1986, pp. 206-214.

${ }^{11}$ Rockwell, D., “Oscillations of Impinging Shear Layers," ALAA Journal, Vol. 21, No. 5, May 1983, pp. $645-664$.

${ }^{12}$ Howe, M. S., Theory of Vortex Sound, Cambridge University Press, Cambridge, UK, 2003, pp. 191-207.

${ }^{13}$ Anthoine, J., Buchlin, J. M., and Guery, J. F., "Effect of Nozzle Cavity on Resonance in Large SRM: Numerical Simulations," Journal of Propulsion and Power, Vol. 19, No. 3, May-June 2003, pp. 374-384.

${ }^{14}$ Balleru, S., Godfroy, F., Guery, J. F., and Ribereau, D., "Assessment on Analysis and Prediction Method Applied on

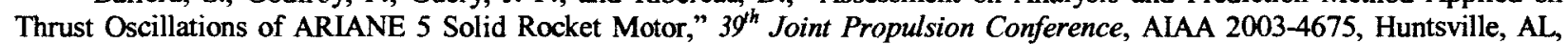
July 2003.

${ }^{15}$ Lupoglazoff, N., Vuillot, F., Dupays, J., and Fabignon, Y., "Numerical Simulations of the Unsteady Flow Inside Segmented Solid-Propellant Motors with Burning Aluminum Particles," $40^{\text {th }}$ AlAA Aerospace Sciences Conference, AIAA 20020784, Reno, NV, January 2002. 